\title{
miR-26a-5p alleviates lipopolysaccharide-induced acute lung injury by targeting the connective tissue growth factor
}

\author{
HONGYAN LI ${ }^{1}$, TINGTING YANG ${ }^{1}$ and ZHAOXIA FEI ${ }^{2}$ \\ ${ }^{1}$ Department of Child Healthcare, Zibo Women \& Children Hospital, Zibo, Shandong $255000 ;{ }^{2}$ General Internal Medicine, \\ Qingdao Hospital of Traditional Chinese Medicine (Qingdao Hiser Hospital), Qingdao, Shandong 266033, P.R. China
}

Received April 10, 2020; Accepted August 18, 2020

DOI: $10.3892 / \mathrm{mmr} .2020 .11643$

\begin{abstract}
The aim of the present study was to investigate the regulatory functions of microRNA (miR)-26a-5p on lipopolysaccharide (LPS)-induced acute lung injury (ALI) and its molecular mechanisms. The role of miR-26a-5p on an ALI mouse model was evaluated by examining the histological changes, wet/dry (W/D) ratio, myeloperoxidase (MPO) activity, malondialdehyde (MDA) expression levels in lung tissues and the survival of ALI mice. Moreover, the protein concentration and the number of neutrophils and lymphocytes in bronchoalveolar lavage fluid (BALF) was analyzed. To explore the effect of miR-26a-5p on inflammatory responses and apoptosis, the expression levels of tumour necrosis factor- $\alpha$ (TNF- $\alpha$ ), interleukin (IL)- $1 \beta$ and IL- 6 and apoptosis were measured by ELISA, terminal deoxynucleotidyl transferase-mediated dUTP nick end labelling staining and flow cytometry in BALF, A549 cells and lung tissues. B-cell lymphoma-2 (Bcl-2), Bax and cleaved caspase-3 in lung tissues were measured by western blotting and reverse transcription-quantitative PCR. Connective tissue growth factor (CTGF) was predicted as a direct target of miR-26a-5p using dual luciferase reporter assay. The present study sought to determine whether CTGF overexpression reversed the effect of miR-26a-5p on apoptosis and inflammatory responses in LPS-induced A549 cells. The data revealed that miR-26a-5p overexpression ameliorated LPS-induced ALI, which was implicated by fewer histopathological changes, W/D ratio, apoptosis in lung tissues and the survival of ALI mice. Moreover, miR-26a-5p overexpression alleviated LPS-induced inflammatory responses in ALI mice via the reduction of total protein, neutrophil and lymphocyte counts and the expression levels of TNF- $\alpha$, IL-1 $\beta$, IL-6, MDA and
\end{abstract}

Correspondence to: Dr Zhaoxia Fei, General Internal Medicine, Qingdao Hospital of Traditional Chinese Medicine (Qingdao Hiser Hospital), 4 Renmin Road, Shibei, Qingdao, Shandong 266033, P.R. China

E-mail: fzx6218@163.com

Key words: acute lung injury, lipopolysaccharide, microRNA-26a-5p, inflammation, apoptosis, connective tissue growth factor
MPO activity in BALF. Similarly, miR-26a-5p overexpression decreased apoptosis and the expression of TNF- $\alpha$, IL-1 $\beta$ and IL-6 in LPS-induced A549 cells. CTGF was a direct target of miR-26a-5p. CTGF overexpression reversed the effect of miR-26a-5p on cell apoptosis and inflammatory responses in LPS-induced A549 cells. The present study demonstrated that miR-26a-5p could attenuate lung inflammation and apoptosis in LPS-induced ALI by targeting CTGF.

\section{Introduction}

Acute lung injury (ALI) is characterized by serious pulmonary inflammatory responses with a high incidence of morbidity and mortality (1). Some progress has been made in developing a therapeutic strategy and etiology, although the mortality rate of patients with ALI remains high (2). Consequently, there is a need to identify innovative therapeutic strategies and effective medications for the benefit of patients with ALI.

MicroRNAs (miRNAs; miRs) are a class of short non-protein coding RNAs with lengths of 19-25 nucleotides, which modulate target gene expression at the posttranscriptional level (3). An increasing number of studies have reported that miRNAs play critical roles in the progression of several lung diseases, including ALI (4-6). For example, Yang et al (5) reported that the upregulation of miR-140-5p protected mice from lipopolysaccharide (LPS)-induced ALI via the myeloid differentiation primary response 88 (MyD88)/NF- $\mathrm{B}$ pathway by targeting Toll-like receptor (TLR)4. Xie et al (6) revealed that the downregulation of miR-34b-5p attenuated inflammatory responses and apoptosis in LPS-induced ALI of mice through targeting progranulin. However, the effect of miR-26a-5p on LPS-induced ALI and its related molecular mechanisms have not yet been reported.

Connective tissue growth factor (CTGF) is a multifunctional matricellular protein that belongs to the CTGF-Cyr61/Cef10-Nov (CCN) family. It was first reported in 1991 by Bradham et al (7). Increasing evidence has demonstrated that CTGF, a downstream effector of transforming growth factor- $\beta 1$ (TGF- $\beta 1$ ), can induce lung injury and contribute to pulmonary fibrosis (8-10). In addition, CTGF has been reported to have an important role in inflammatory diseases including rheumatoid arthritis, inflammatory kidney diseases and silicosis (11). Previous studies have suggested that miRNAs, such as miR-18a, regulates lung injury 
by modulating the expression of CTGF and the TGF- $\beta 1$ pathway (12). However, whether miR-26a-5p exerts beneficial effects on the progression of LPS-induced ALI by modulating CTGF remains unclear.

The present research aimed to identify the potential effects of miRNA-26a-5p on LPS-induced ALI and its related molecular mechanisms in vitro and in vivo. These data confirmed that miR-26a-5p could attenuate lung inflammation and apoptosis in LPS-induced ALI by targeting CTGF. Thus, miR-26a-5p may serve as an important target for the treatment of ALI.

\section{Materials and methods}

Animals. A total of 230 male C57BL/6 mice (6-8 weeks; 20-25 g) were obtained from Beijing Vital River Laboratory Animal Technology Co., Ltd. All mice were housed in climate-controlled quarters with a 12-h light/dark cycle and provided water and standard laboratory chow ad libitum. The experimental procedures were performed in accordance with the Guide for the Care and Use of Laboratory Animals and approved by the Ethics committee of Zibo Women \& Children Hospital.

Experimental protocol and animal models of ALI. The mice were intratracheally injected with $5 \mathrm{mg} / \mathrm{kg}$ LPS (Beijing Solabio Science \& Technology C., Ltd.), dissolved in phosphate buffer saline (PBS). A total of $24 \mathrm{~h}$ prior to LPS treatment, the mice were administered with intraperitoneal injections of miR-26a-5p mimic (20 mg/kg) or miR-26a-5p mimic negative control (NC) $(20 \mathrm{mg} / \mathrm{kg})$ twice per day for 2 days consecutively. Subsequently, the mice were randomly divided into five groups ( $n=38 /$ group): Control group (normal mice without any treatment), Sham group (received PBS), LPS group (received LPS), LPS + mimic negative control (NC) group (received LPS and miR-26a-5p mimic NC) and LPS + miR-26a-5p mimic group (received LPS and miR-26a-5p mimic). All mice were sacrificed by cervical dislocation under anesthesia via intraperitoneal injection of $50 \mathrm{mg} / \mathrm{kg}$ pentobarbital sodium at $24 \mathrm{~h}$ after LPS treatment for the subsequent experiment. The criteria used to confirm death were as follows: Cessation of heartbeat for more than $5 \mathrm{~min}$ and no pupillary reflex to strong light. The miR-26a-5p mimic and miR-26a-5p mimic NC were purchased from Takara Biotechnology Co., Ltd. The sequences used were as follows: miR-26a-5p mimic, 5'-UUC AAGUAAUCCAGGAUAGGCU-3' (sense); 5'-CCUAUCCUG GAUUACUUGAAUU-3' (antisense); and miR-26a-5p mimic NC, 5'-UUCUCCGAACGUGUCACGUTT-3' (sense); 5'-ACG UGACACGUUCGGAGAATT-3' (antisense).

In addition, survival experiments were performed in the four mice groups ( $n=10 /$ group; Sham, LPS, LPS + mimic $\mathrm{NC}$, LPS + miR-26a-5p mimic). The survival of mice was monitored for $84 \mathrm{~h}$.

Lung wet/dry (W/D) weight ratio. Lung edema was evaluated according to the wet/dry weight ratio of lung tissues. After the mice $(n=6)$ were sacrificed, the right lungs were excised and immediately weighed to obtain the wet weight. Subsequently, the lung samples were dried at $80^{\circ} \mathrm{C}$ for $48 \mathrm{~h}$ to obtain the dry weight (Lung wet/dry ratio=wet weight/dry weight).
Myeloperoxidase (MPO) and malondialdehyde (MDA) assay. After the mice $(n=6)$ were sacrificed, the right lung tissues were collected and homogenized in 4-(2-hydroxyethyl)-1-piperazineethanesulfonic acid containing $0.5 \%$ cetyltrimethyl ammonium bromide. Then, the activity of MPO (cat. no. A044) and the content of MDA (cat. no. A003-1) were measured by using the corresponding test kits obtained from Nanjing Jiancheng Bioengineering Institute in accordance with the manufacturer's instructions.

Protein concentration and cell counts in bronchoalveolar lavage fluid $(B A L F)$. After the mice $(n=6)$ were sacrificed, the BALF was collected by injection and retraction of $1.5 \mathrm{ml}$ PBS three times, and was centrifuged at 1,200 $\mathrm{x} g$ for $10 \mathrm{~min}$ at $4^{\circ} \mathrm{C}$. Subsequently, the supernatants were collected for the assessment of total protein concentration by the bicinchoninic acid (BCA) method. The cell pellet was resuspended in PBS, and the neutrophil and lymphocyte counts were determined using a hemocytometer following Wright-Giemsa staining for $10 \mathrm{~min}$ at room temperature.

Hematoxylin and eosin $(H \& E)$ staining. After the mice $(n=5)$ were sacrificed, the right lung tissues were collected and fixed in $4 \%$ formaldehyde at room temperature for $24 \mathrm{~h}$. Then, the lung tissues were dehydrated in graded concentrations of ethanol, embedded in paraffin, and transversely cut into 5- $\mu \mathrm{m}$ thick sections. Finally, the histological changes in lung tissues were analyzed by H\&E staining under an optical microscope (magnification, x100). In addition, the histological score of the lung tissues was calculated by assessing the alveolar congestion, hemorrhage, inflammatory cell infiltration and alveolar wall thickness, and graded according to a five-point scale from 0 to 4 as follows: $0=$ no damage, $1=$ mild damage, $2=$ moderate damage, $3=$ severe damage and $4=$ very severe damage (13).

Terminal deoxynucleotidyl transferase-mediated dUTP nick end labelling (TUNEL) staining. After the mice $(\mathrm{n}=5)$ were sacrificed, the apoptotic cells in the harvested lung tissues were detected by using the TUNEL staining kit supplied by Shanghai Ruisai Biotechnology Co., Ltd. following the manufacturer's protocol. Five random fields were viewed in each section and the rate of positive cells was analyzed under a fluorescence microscope at a magnification of $x 400$.

Cell culture and transfection. The human type II alveolar epithelial cells (A549), supplied by American Type Culture Collection, were maintained in Dulbecco's Modified Eagle's Medium (DMEM; Gibco; Thermo Fisher Scientific, Inc.), supplemented with $10 \%$ fetal bovine serum (FBS; Invitrogen; Thermo Fisher Scientific, Inc.) and $1 \%$ penicillin/streptomycin (Invitrogen; Thermo Fisher Scientific, Inc.) at $37^{\circ} \mathrm{C}$ in a humidified atmosphere with 5\% $\mathrm{CO}_{2}$. The miR-26a-5p mimic, pcDNA3.1-CTGF and their negative controls were obtained from Takara Biotechnology Co., Ltd. Briefly, $10 \mathrm{nM}$ miR-26a-5p mimic or pcDNA3.1-CTGF were transfected into A549 cells $\left(6 \times 10^{6}\right)$ using Lipofectamine $^{\circledR} 3000$ (Invitrogen; Thermo Fisher Scientific, Inc.), at room temperature for $48 \mathrm{~h}$ according to the manufacturer's protocol. The transfected A549 cells were randomly divided into the Control group (no treatment), LPS group (treated with LPS), LPS + mimic NC group (treated with LPS 
and miR-26a-5p mimic negative control), LPS + miR-26a-5p mimic group (treated with LPS and miR-26a-5p mimic), LPS + miR-26a-5p mimic + oe-CTGF NC group (treated with LPS, miR-26a-5p mimic and pcDNA3.1-CTGF NC) and LPS + miR-26a-5p mimic + oe-CTGF (treated with LPS, miR-26a-5p mimic and pcDNA3.1-CTGF). After transfection for $48 \mathrm{~h}$, the A549 cells were treated with LPS (Sigma-Aldrich; Merck $\mathrm{KGaA}$ ) for $24 \mathrm{~h}$ and analyzed.

Cell viability assay. To assess cell viability, 3-(4,5-dimethylthiazol-2-yl)-2,5-diphenyltetrazolium bromide (MTT) assay was used. The transfected A549 cells were seeded into 96-well plates at a density of $1 \times 10^{3}$ cells/well. After $24 \mathrm{~h}$ of LPS stimulation, A549 cells were incubated with $20 \mu 1$ of MTT at a final concentration of $5 \mathrm{mg} / \mathrm{ml}$ (Sigma-Aldrich; Merck KGaA) in the dark for $4 \mathrm{~h}$. Subsequently, dimethyl sulfoxide (DMSO, $150 \mu \mathrm{l}$ ) was added to each well. Finally, the cell viability was determined by measuring absorbances at $490 \mathrm{~nm}$ by using a microplate reader.

Flow cytometry. The A549 cells undergoing apoptosis were detected with an Annexin V-fluorescein isothiocyanate (FITC) apoptosis detection kit (BD Biosciences) following the manufacturer's instructions. Briefly, $24 \mathrm{~h}$ after LPS stimulation, the A549 cells from different groups were harvested, washed with PBS and resuspended in Annexin-binding buffer. Propidium iodide (PI) and FITC-conjugated Annexin V were added into the cell suspensions and maintained in the dark for $15 \mathrm{~min}$ at $37^{\circ} \mathrm{C}$. The apoptotic cells were then analyzed using a flow cytometer (BD FACScalibur; BD Biosciences).

Enzyme-linked immunosorbent assay (ELISA). The levels of interleukin (IL)-1 $\beta$, IL-6 and tumor necrosis factor (TNF)- $\alpha$ in mice BALF $(n=6)$ and A549 cells were determined using an ELISA kit (BioLegend, Inc.) in accordance with the manufacturer's instructions. The ELISA kits for mice BALF were as follows: IL-1 $\beta$ (cat. no. 432601), IL-6 (cat. no. 431304) and TNF- $\alpha$ (cat. no. 430904). The ELISA kits for A549 cells were as follows: IL-1 $\beta$ (cat. no. 579409), IL-6 (cat. no. 430504) and TNF- $\alpha$ (cat. no. 430204).

Dual luciferase reporter gene assay. TargetScan (14) was used to predict the targeting relationship between miR-26a-5p and CTGF. The 3'-untranslated region (3'-UTR) of CTGF, with wild-type or mutant binding sites for miR-26a-5p, was amplified and cloned into the pGL3 luciferase vector (Promega Corporation) to generate the plasmid pGL3-WT-CTGF-3'-UTR (CTGF-WT) or pGL3-Mut-CTGF-3'-UTR (CTGF-MT). For the luciferase reporter assay, A549 cells were co-transfected with reporter vectors and miR-26a-5p mimics or miR-26a-5p mimics NC using Lipofectamine ${ }^{\circledR} 3000$ (Invitrogen; Thermo Fisher Scientific, Inc.). A total of $48 \mathrm{~h}$ after the transfection, luciferase activity was detected by using a dual luciferase kit (Promega Corporation). Firefly luciferase activity was normalized to Renilla luciferase activity.

$R N A$ extraction and reverse transcription-quantitative PCR $(R T-q P C R)$. Lung tissue was collected after the mice $(\mathrm{n}=5)$ were sacrificed. Total RNA was extracted from A549 cells and lung tissues by TRIzol ${ }^{\circledR}$ Reagent (Thermo Fisher
Scientific, Inc.), based on the manufacturer's protocols. Total RNA ( $2 \mu \mathrm{g})$ was added to the reverse transcription reaction to synthesize complementary DNA (cDNA) using SuperScript ${ }^{\mathrm{TM}}$ IV First-Strand Synthesis System (Invitrogen; Thermo Fisher Scientific, Inc.). Thereafter, RT-qPCR was performed on a 7500 Real-time PCR System with MirVana ${ }^{\text {TM }}$ qRT-PCR miRNA (Invitrogen; Thermo Fisher Scientific, Inc.). The PCR reaction conditions were as follows: $95^{\circ} \mathrm{C}$ for $10 \mathrm{~min}$ followed by 40 cycles at $95^{\circ} \mathrm{C}$ for $10 \mathrm{sec}, 60^{\circ} \mathrm{C}$ for $20 \mathrm{sec}$, and $72^{\circ} \mathrm{C}$ for $30 \mathrm{sec}$. The primers used in the present study were as follows: miR-26a-5p forward (F), 5'-GGATCCGCAGAAACTCCA GAGA-3' and reverse (R), 5'-TTGGAGGAAAGACGATTT CCGT-3'; U6 F, 5'-GCGCGTCGTGTAAAGCGTTC-3' and R, 5'-GTGCAGGGTCCGAGGT-3'; CTGF F, 5'-CAAGGG CCTCTTCTGTGACT-3' and R, 5'-ACGTGCACTGGTACT TGCAG-3'; B-cell lymphoma-2 (Bcl-2) F, 5'-ATGTGTGTG GAGAGCGTCAA-3' and R, 5'-GCCGGTTCAGGTACT CAGTC-3'; Bax F: 5'-TCTGACGGCAACTTCAACTG-3', R: 5'-GGAGGAAGTCCAATGTCCAG-3'; cleaved caspase-3 F: 5'-CTCGGTCTGGTACAGATGTCG-3', R: 5'-TGGCTCAGA AGCACACAAAC-3'; GAPDH F, 5'-GCACCGTCAAGGCTG AGAAC-3' and R, 5'-ATGGTGGTGAAGACGCCAGT-3'. For the normalization of the expression levels, U6 and GAPDH were used as internal controls. The relative expression levels were calculated using the $2^{-\Delta \Delta \mathrm{Cq}}$ method (15).

Western blot analysis. Lung tissue was collected after the mice $(n=5)$ were sacrificed. Total proteins were extracted from A549 cells and lung tissues by using lysis buffer (Beijing Solarbio Science \& Technology Co., Ltd.) containing phenylmethylsulfonyl fluoride (PMSF). The concentration of proteins was measured with a BCA protein assay kit (Beyotime Institute of Biotechnology). Protein samples (50 $\mu \mathrm{g}$ ) were loaded on $10 \%$ sodium dodecyl sulfate-polyacrylamide gel for electrophoresis and then transferred onto polyvinylidene difluoride (PVDF) membranes (Merck KGaA). After blocking with 5\% skimmed milk for $2 \mathrm{~h}$ at room temperature, the membranes were incubated at $4{ }^{\circ} \mathrm{C}$ overnight with the following primary antibodies supplied by Cell Signaling, Inc.: Bax (1:1,000; product no. 14796), cleaved caspase-3 (1:1,000; product no. 9661), Bcl-2 (1:1,000; product no. 3498), CTGF (1:1,000; product no. 86641) and GAPDH (1:1,000; product no. 5174). After washing with TBST (20\% Tween-20) three times, the membranes were incubated with the horseradish peroxidase-conjugated anti-rabbit IgG secondary antibody (1:5,000; cat. no. 7040; Cell Signaling Technology, Inc.) at room temperature for $1 \mathrm{~h}$. Finally, the protein bands were visualized with an ECL system (Thermo Fisher Scientific, Inc.) and then analyzed by using Image $\mathrm{Lab}^{\mathrm{TM}}$ Software (version 3.0; Bio-Rad Laboratories, Inc.).

Statistical analysis. The statistical analysis was performed using SPSS 23.0 software (IBM Corp.). Data in the present study are presented as the mean \pm standard deviation (SD). Statistical differences were analyzed using the unpaired Student's t-test or one-way analysis of variance with Tukey's multiple comparison post-hoc test. Survival rates were assessed by the Kaplan-Meier method, and survival curves were compared by log-rank tests. $\mathrm{P}<0.05$ was considered to indicate a statistically significant difference. All experimental data were obtained from at least three independent experiments. 


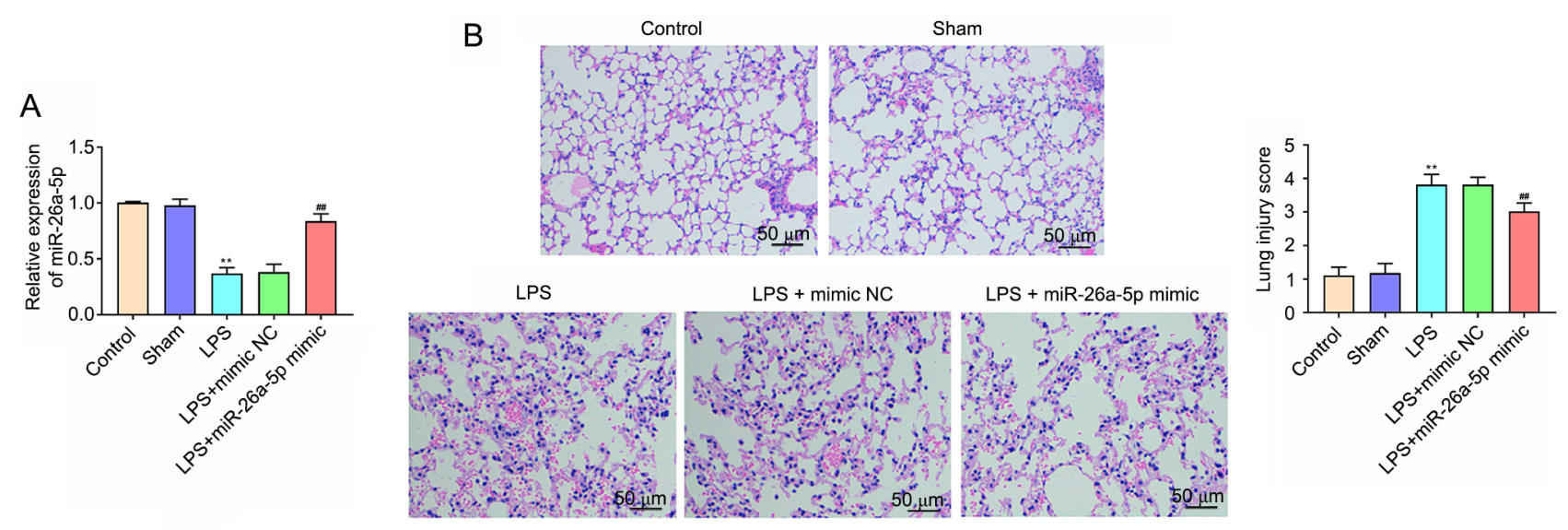

C

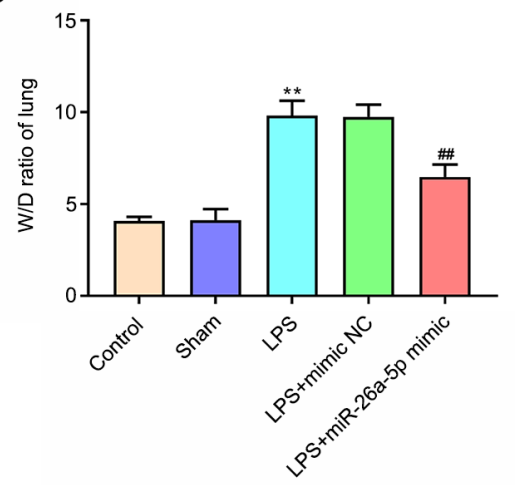

D

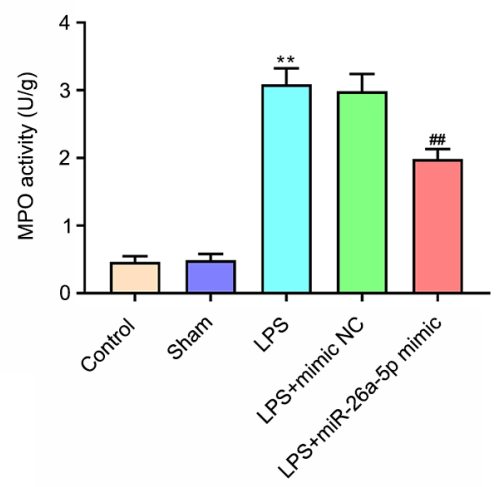

$\mathrm{E}$

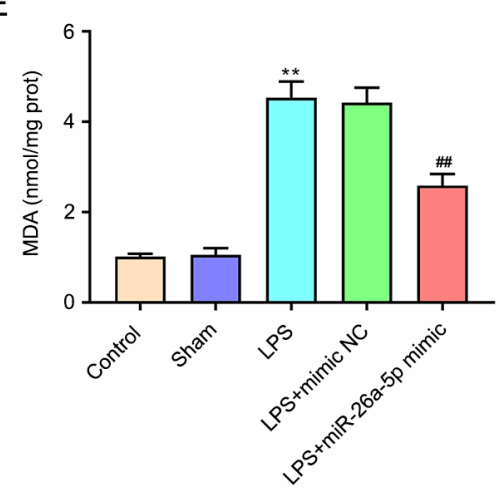

$\mathrm{F}$

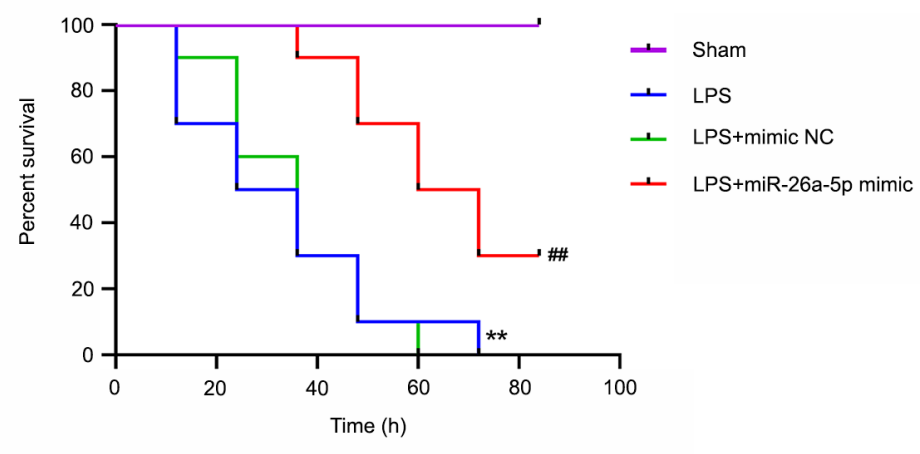

Figure 1. Overexpression of miR-26a-5p alleviates LPS-induced acute lung injury in mice. Mice in each group underwent intraperitoneal injection of miR-26a-5p mimics or NC mimics $(20 \mathrm{mg} / \mathrm{kg}$ ) $24 \mathrm{~h}$ before treatment with $5 \mathrm{mg} / \mathrm{kg}$ LPS. Mice were sacrificed after LPS administration for $24 \mathrm{~h}$ and then lung tissues were collected for analysis (except the survival experiment). (A) The expression of miR-26a-5p in lung tissues was detected by reverse transcription-quantitative PCR ( $n=5 /$ group). (B) Pathological changes in the lung tissues observed by H\&E staining (x100, magnification) ( $\mathrm{n}=5 /$ group). (C) The lung W/D weight ratio was assessed among the experimental groups (n=6/group). The activity of (D) MPO and the content of (E) MDA in lung tissues were detected using the corresponding test kits ( $\mathrm{n}=6 /$ group). (F) The survival rates were observed during $84 \mathrm{~h}$ following LPS treatment ( $\mathrm{n}=10 / \mathrm{group})$. Data were presented as the mean $\pm \mathrm{SD} .{ }^{* *} \mathrm{P}<0.01$ vs. Sham group; ${ }^{\# /} \mathrm{P}<0.01$ vs. LPS + mimic NC group. miR, microRNA; NC, negative control; LPS, lipopolysaccharide; W/D, weight/dry; MDA, malondialdehyde; MPO, myeloperoxidase.

\section{Results}

Overexpression of miR-26a-5p alleviates LPS-induced acute lung injury in mice. The results of RT-qPCR revealed that the expression of miR-26a-5p was significantly decreased in the LPS group compared with the Sham group $(\mathrm{P}<0.01$; Fig. 1A). Compared with the LPS + mimic NC group, the expression of miR-26a-5p was significantly increased in the
LPS + miR-26a-5p mimic group ( $\mathrm{P}<0.01$; Fig. 1A). In addition, to explore the effect of miR-26a-5p on LPS-induced ALI, H\&E staining and the W/D ratio of lung tissue were performed. As revealed in Fig. 1B, after the administration of LPS, the pulmonary edema, hemorrhage, alveolar wall thickening and inflammatory cell infiltration were markedly increased. Additionally, miR-26a-5p overexpression significantly ameliorated the histological changes induced by LPS (Fig. 1B). Lung 
A

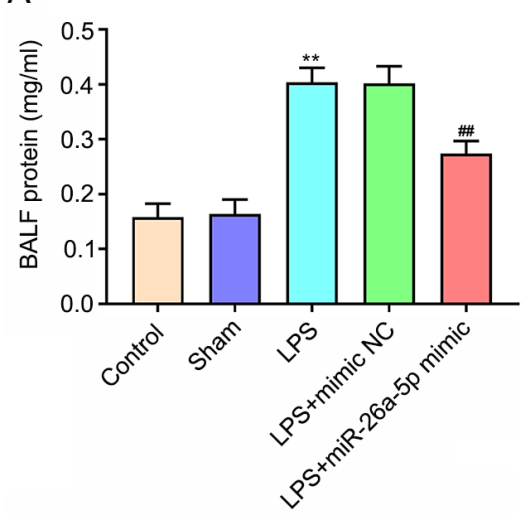

D

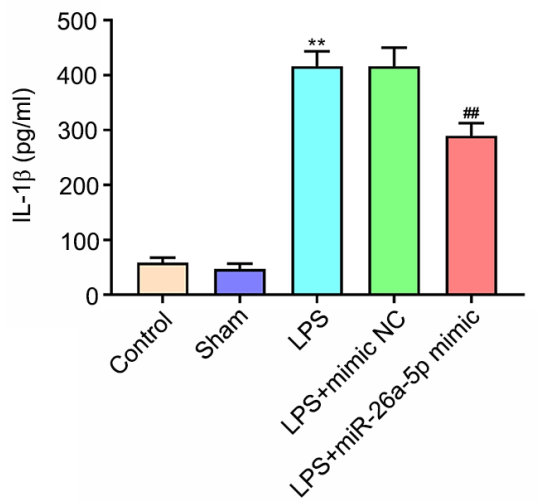

B

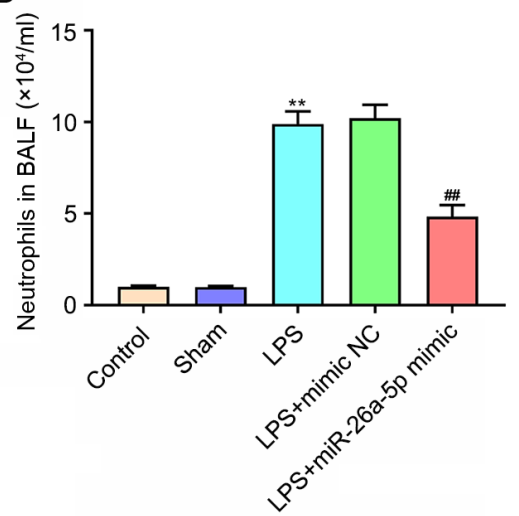

E

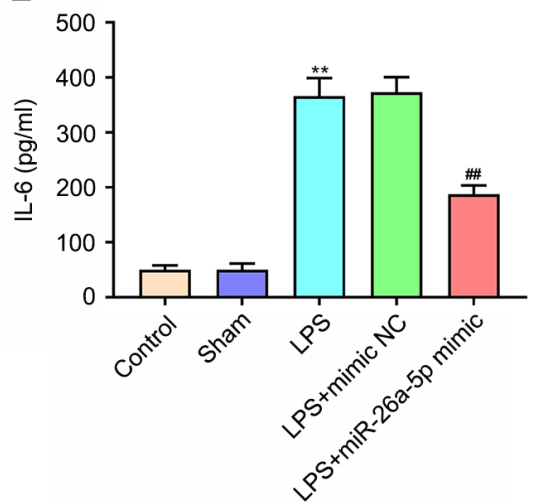

C

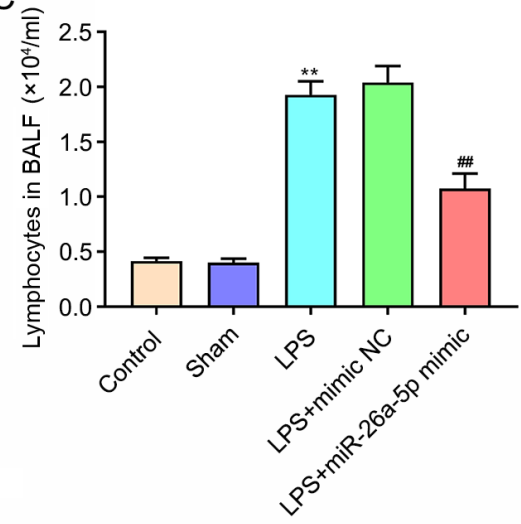

F

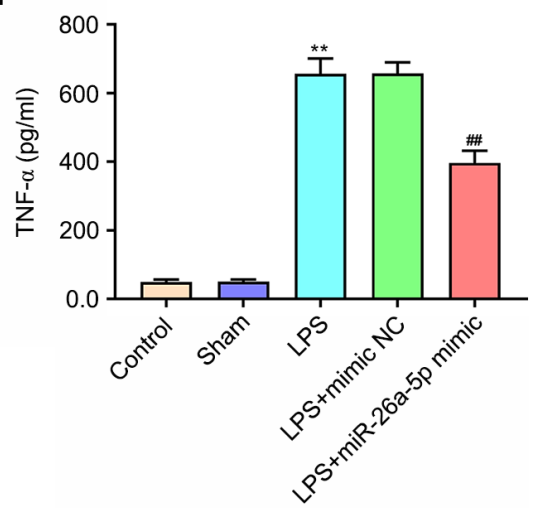

Figure 2. Overexpression of miR-26a-5p alleviates lung tissue inflammation in LPS-induced acute lung injury mice. Mice in each group underwent intraperitoneal injection of miR-26a-5p mimics or NC mimics $(20 \mathrm{mg} / \mathrm{kg}) 24 \mathrm{~h}$ before treatment with $5 \mathrm{mg} / \mathrm{kg}$ LPS. And mice were sacrificed after LPS administration for $24 \mathrm{~h}$ and then BALF were collected for analysis. (A) The total protein concentration in BALF was measured by BCA method ( $\mathrm{n}=6 / \mathrm{group}$ ). The number of (B) neutrophils and (C) lymphocytes in BALF was determined using a hemocytometer (n=6/group). The expression level of (D) IL-1 $\beta$, (E) IL-6 and (F) TNF- $\alpha$ in BALF was detected by ELISA ( $\mathrm{n}=6$ /group). Data are presented as the mean $\pm \mathrm{SD}$. ${ }^{* *} \mathrm{P}<0.01$ vs. Sham group; ${ }^{\# \#} \mathrm{P}<0.01$, vs. LPS + mimic NC group. miR, microRNA; NC, negative control; LPS, lipopolysaccharide; BALF, bronchoalveolar lavage fluid.

injury scores also confirmed the result. Moreover, Fig. 1C revealed that the lung wet/dry weight ratio was significantly increased in the group treated with LPS compared with the Sham group $(\mathrm{P}<0.01)$. When compared with the LPS + mimic NC group, miR-26a-5p mimic significantly decreased the lung W/D ratio $(\mathrm{P}<0.01)$. As revealed in Fig. $1 \mathrm{D}$ and $\mathrm{E}$, the activity of MPO and MDA content was significantly increased in LPS group compared with that of the Sham group $(\mathrm{P}<0.01)$. Correspondingly, upregulation of MPO and MDA was reversed by the overexpression of miR-26a-5p $(\mathrm{P}<0.01)$. In addition, the results revealed that LPS group mice survival rate was significantly reduced compared with the Sham group mice $(\mathrm{P}<0.01$; Fig. 1F). Conversely, the mice survival rate in the LPS + miR-26a-5p mimic group was significantly longer than the LPS + mimic NC group $(\mathrm{P}<0.01$; Fig. $1 \mathrm{~F})$. Collectively, the results indicated that the overexpression of miR-26a-5p could alleviate LPS-induced ALI in mice.

Overexpression of miR-26a-5p alleviates lung tissue inflammation in LPS-induced ALI mice. The protein expression levels and the number of neutrophils and lymphocytes in BALF were significantly increased in the LPS group compared with the Sham group ( $\mathrm{P}<0.01$; Fig. $2 \mathrm{~A}-\mathrm{C})$. In contrast, miR-26a-5p overexpression significantly decreased the upregulation induced by LPS $(\mathrm{P}<0.01)$. The ELISA results confirmed that the expression of IL-1 $\beta$, IL-6 and TNF- $\alpha$ were significantly increased after the administration of LPS $(\mathrm{P}<0.01$; Fig. 2D-F). Furthermore, the upregulation of IL-1 $\beta$, IL- 6 and TNF- $\alpha$ was reversed by the overexpression of miR-26a-5p ( $\mathrm{P}<0.01$; Fig. 2D-F). These results revealed that the overexpression of miR-26a-5p could alleviate lung tissue inflammation in LPS-induced ALI in mice.

Overexpression of miR-26a-5p decreases lung tissue cell apoptosis in LPS-induced ALI mice. To evaluate the cell apoptosis in lung tissues, TUNEL staining was performed (Fig. 3A). The number of apoptotic cells in the lung tissues in the LPS group was significantly increased compared with that in the Sham group $(\mathrm{P}<0.01)$. miR-26a-5p overexpression also significantly reduced the LPS-induced apoptosis of lung cells $(\mathrm{P}<0.01)$. In addition, apoptosis-related proteins were detected via RT-qPCR and western blotting. The results of Fig. 3B-H demonstrated that the mRNA and protein expression levels of Bcl-2 in the LPS treatment group were lower than those in the Sham group $(\mathrm{P}<0.01)$, whereas the expression levels of Bax and cleaved caspase-3 were significantly higher $(\mathrm{P}<0.01)$. In addition, the overexpression of miR-26a-5p significantly reversed these effects on Bcl-2, Bax and cleaved caspase-3 $(\mathrm{P}<0.01)$. All data indicated that the overexpression of miR-26a-5p could decrease lung tissue cell apoptosis in LPS-induced ALI in mice. 

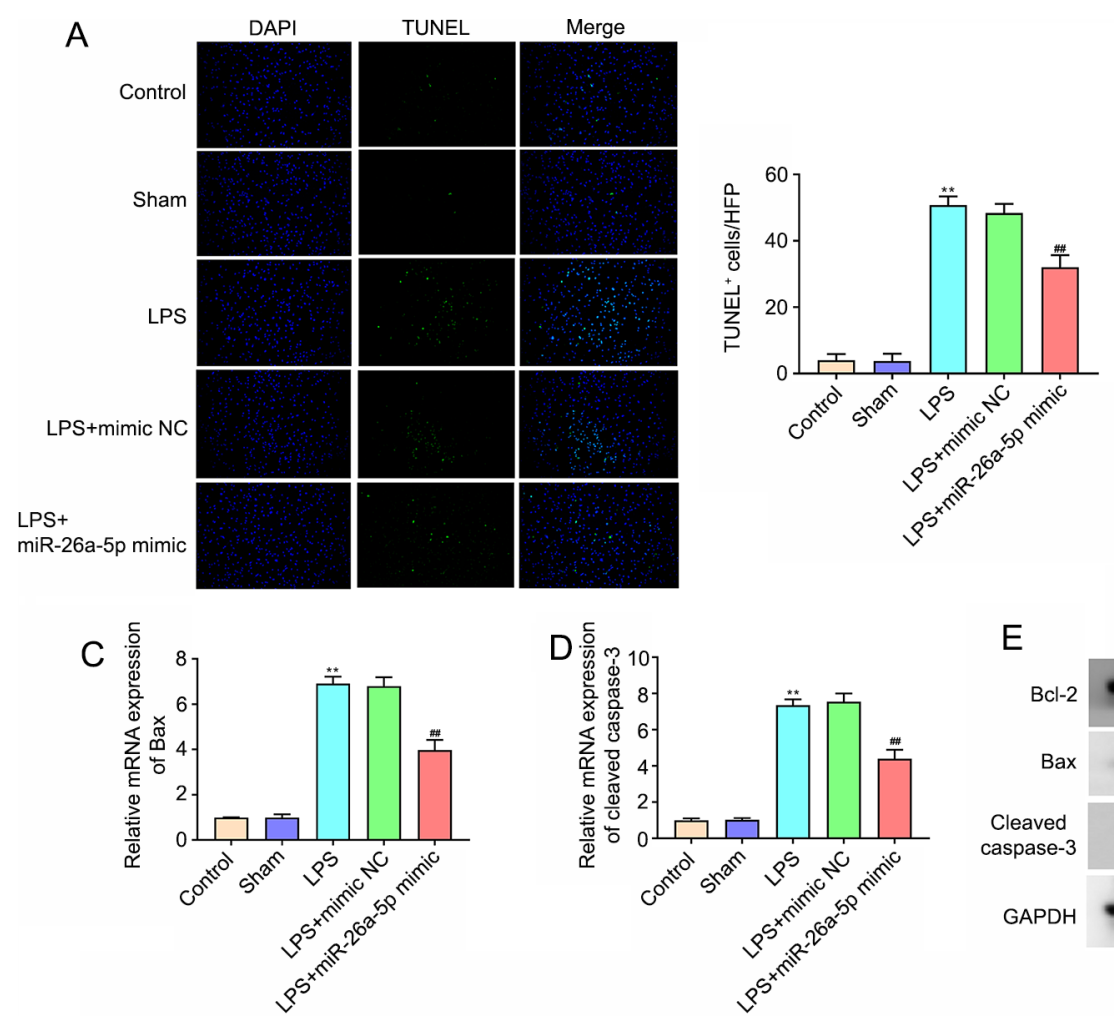

B
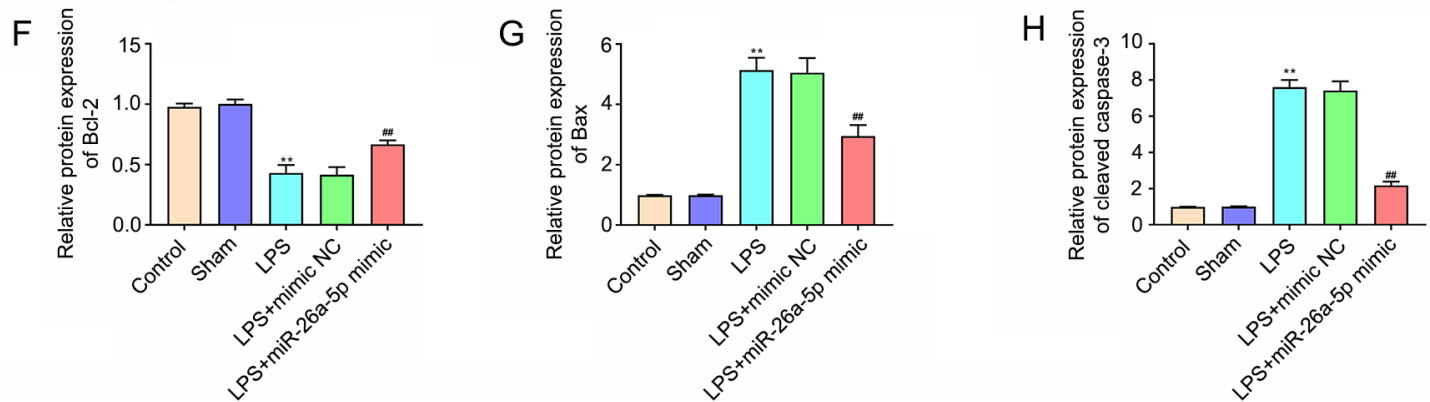

Figure 3. Overexpression of miR-26a-5p decreases lung tissue cell apoptosis in LPS-induced acute lung injury mice. Mice in each group were intraperitoneal injection of miR-26a-5p mimics or NC mimics $(20 \mathrm{mg} / \mathrm{kg}) 24 \mathrm{~h}$ before treatment with $5 \mathrm{mg} / \mathrm{kg} \mathrm{LPS}$. And mice were sacrificed after LPS administration for $24 \mathrm{~h}$ and then lung tissues were collected for analysis. (A) Apoptotic cells in the lung tissues were detected by TUNEL staining (magnification, $\mathrm{x} 400)$ ( $\mathrm{n}=5 / \mathrm{group}$ ). The mRNA expression of (B) Bcl-2, (C) Bax and (D) cleaved caspase-3 in the lung tissues was detected by reverse transcription-quantitative PCR (n=5/group). (E) Representative western blot bands of Bcl-2, Bax and cleaved caspase-3. (F) Semi-quantitative data for the level of (F) Bcl-2, (G) Bax and (H) cleaved caspase-3 expression ( $n=5 /$ group). Data were presented as the mean $\pm \mathrm{SD}$. ${ }^{* *} \mathrm{P}<0.01$ vs. Sham group; ${ }^{\# \#} \mathrm{P}<0.01$ vs. LPS + mimic NC group. miR, microRNA; NC, negative control; LPS, lipopolysaccharide; TUNEL, Terminal deoxynucleotidyl transferase-mediated dUTP nick end labelling.

Overexpression of miR-26a-5p decreases apoptosis and inflammatory responses in LPS-induced A549 cells. As revealed in Fig. 4A, the expression of miR-26a-5p in LPS-treated cells was significantly decreased compared with the untreated cells in a dose-dependent manner $(\mathrm{P}<0.05$, $\mathrm{P}<0.01)$. A concentration of $20 \mu \mathrm{g} / \mathrm{ml}$ LPS was selected for subsequent experiments. Transfection efficacy was confirmed by the significantly augmented expression of miR-26a-5p at the mRNA expression level in A549 cells transfected with the miR-26a-5p mimic (Fig. 4B). MTT assay results confirmed that the administration of LPS significantly restricted cell viability $(\mathrm{P}<0.01$; Fig. 4C). Correspondingly, miR-26a-5p overexpression significantly increased the cell viability of A549 cells relative to the LPS + mimic NC group $(\mathrm{P}<0.01)$, which indicated that miR-26a-5p overexpression increased the viability of LPS-induced A549 cells. In addition, the results of flow cytometry (Fig. 4D) revealed that the administration of LPS significantly promoted A549 cell apoptosis $(\mathrm{P}<0.01)$. However, the overexpression of miR-26a-5p significantly reduced the cell apoptosis induced by LPS $(\mathrm{P}<0.05)$. The present study also detected inflammatory cytokines in A549 cells and determined that the expression levels of IL-1 $\beta$, IL- 6 and TNF- $\alpha$ were significantly increased after LPS administration $(\mathrm{P}<0.01$; Fig. 4E-G). The upregulation of IL-1 $\beta$, IL-6 and TNF- $\alpha$ was significantly reversed by the overexpression of miR-26a-5p $(\mathrm{P}<0.01)$. Altogether, the present data indicated that the overexpression of miR-26a-5p could decrease apoptosis and inflammatory responses in LPS-induced A549 cells.

$C T G F$ is the target gene of miR-26a-5p. TargetScan predicted that the binding site of miR-26a-5p was the 3'-UTR region in CTGF (Fig. 5A). The dual luciferase reporter gene assay results revealed that the overexpression of miR-26a-5p significantly decreased the luciferase activity in the CTGF-WT 
A

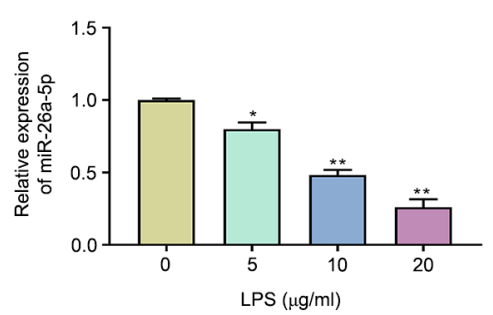

B

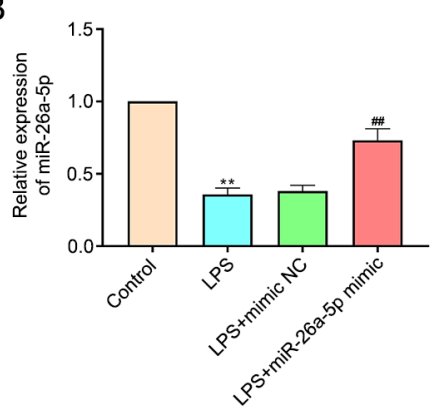

C

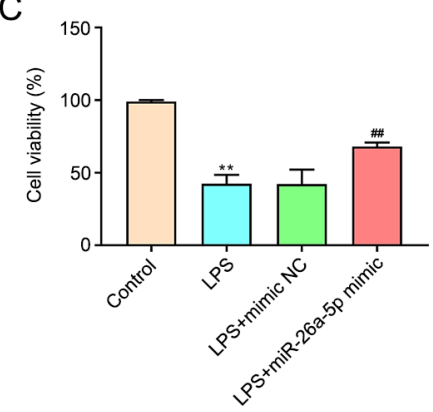

$\mathrm{D}$
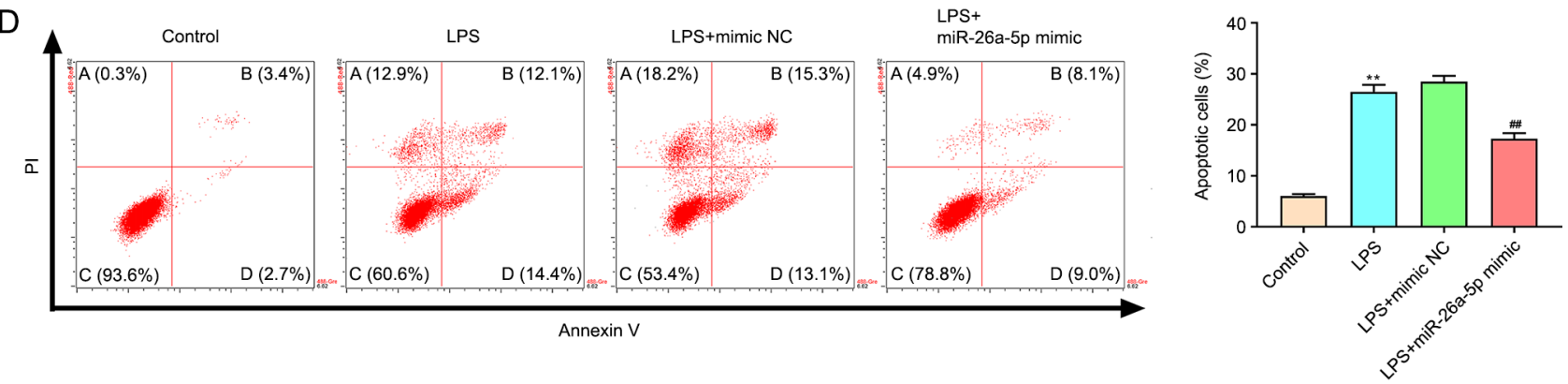

E

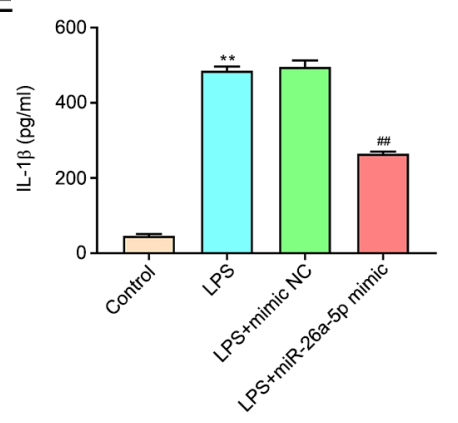

F

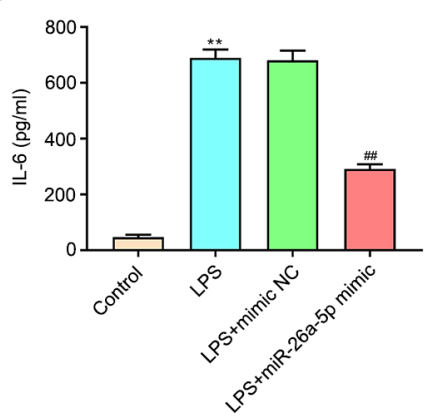

G

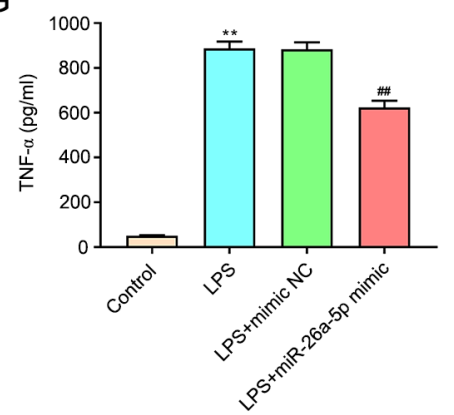

Figure 4. Overexpression of miR-26a-5p decreases apoptosis and inflammatory responses in LPS-induced A549 cells. A549 cells were transfected with miR-26a-5p mimic or mimic NC (10 nM), and then treated with LPS for $24 \mathrm{~h}$, followed by the assessment of cell apoptosis and inflammatory response. (A) The expression of miR-26a-5p was detected by reverse transcription-quantitative PCR in A549 cells treated with various concentrations ( 0,5 , 10 and $20 \mu \mathrm{g} / \mathrm{ml})$ of LPS. (B) The expression of miR-26a-5p was detected in transfected A549 cells. (C) The cell viability was measured by MTT assay in transfected A549 cells. (D) Apoptotic cells were detected by flow cytometry in transfected A549. The expression levels of (E) IL-1 $\beta$, (F) IL-6 and (G) TNF- $\alpha$ were detected by ELISA in transfected A549 cells. Data were presented as the mean $\pm \mathrm{SD}$. (A) ${ }^{*} \mathrm{P}<0.05,{ }^{* *} \mathrm{P}<0.01$ vs. LPS $(0 \mu \mathrm{g} / \mathrm{ml})$ group. (B-G) ${ }^{* *} \mathrm{P}<0.01$ vs. Control group; ${ }^{\# \#} \mathrm{P}<0.01$ vs. LPS + mimic NC group. miR, microRNA; NC, negative control; LPS, lipopolysaccharide.

group $(\mathrm{P}<0.01$; Fig. 5B); however, it had no significant effect on the luciferase activity in CTGF-MT group $(\mathrm{P}>0.05$; Fig. 5B). Furthermore, the study further elucidated whether miR-26a-5p negatively regulated CTGF in A549 cells by RT-qPCR (Fig. 5C) and western blotting (Fig. 5D). The results revealed that the mRNA and protein expression levels of CTGF in the LPS group were higher than those in the Control group $(\mathrm{P}<0.01)$. miR-26a-5p also significantly reversed the effect of LPS on CTGF in a dose-dependent manner. These results indicated that CTGF was a target gene of miR-26a-5p.

miR-26a-5p inhibits apoptosis and inflammatory responses via targeting CTGF in A549 cells. As revealed in Fig. 6A and B, the transfection efficacy of pcDNA3.1-CTGF, the CTGF overexpression plasmid, was confirmed by the significantly enhanced expression of CTGF at the mRNA and protein expression levels in A549 cells. In addition, the results of Fig. 6C-G revealed that CTGF overexpression significantly increased cell apoptosis and the expression levels of IL-1 $\beta$, IL-6 and TNF- $\alpha$, and decreased cell viability $(\mathrm{P}<0.01)$. Moreover, the overexpression of CTGF significantly reversed the effects of miR-26a-5p mimic on cell viability, apoptosis and inflammatory cytokines in LPS-induced A549 cells $(\mathrm{P}<0.01)$. Collectively, this data indicated that miR-26a-5p could inhibit apoptosis and inflammatory responses via targeting CTGF in A549 cells.

\section{Discussion}

ALI is a serious lung disease that is often accompanied by acute inflammatory responses and can lead to respiratory failure (16). At present, the five-year survival rate of patients with ALI is reported to be lower than 50\% (17). Therefore, further studies focusing on the development of novel therapeutic targets for the treatment of ALI are required. This research has confirmed that miR-26a-5p could attenuate lung inflammation and apoptosis in LPS-induced ALI by targeting CTGF. 
A

3' UTR of CTGF WT 5 ' ... ACUCAUUAGACUGGAACUUGAAC ... 3' hsa-miR-26a-5p 3' UCGGAUAGGACCUAAUGAACUU 5

3' UTR of CTGF MT 5' ... ACUCAUUAGACUGGAUGAACUUC ... 3'

B

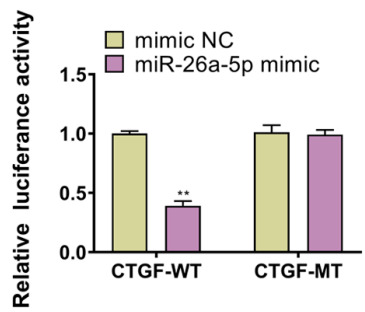

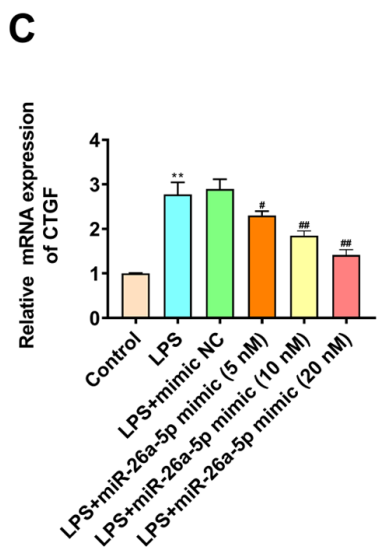

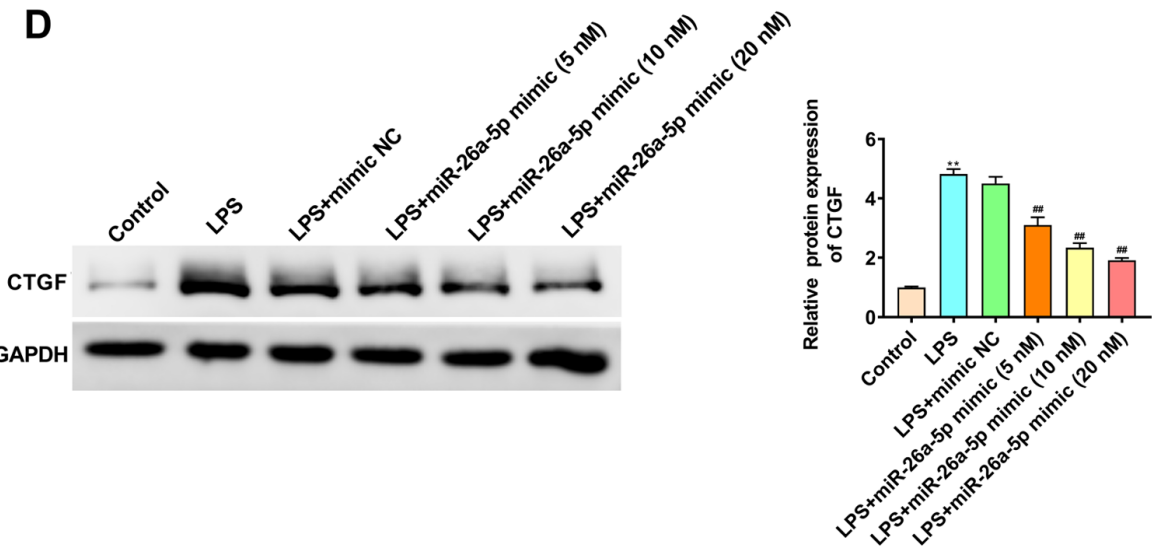

Figure 5. CTGF is the target gene of miR-26a-5p. (A) The binding target of miR-26a-5p and CTGF was predicted by TargetScan software 7.2. (B) Luciferase activity of CTGF-WT and CTGF-MT following the co-transfection of miR-26a-5p mimic or mimic NC in A549 cells detected by dual-luciferase reporter gene assay. (C) The mRNA expression of CTGF was detected by reverse transcription-quantitative PCR in A549 cells transfected with mimic NC or various concentrations $(5,10$ and $20 \mathrm{nM}$ ) of miR-26a-5p. (D) The protein expression of CTGF was detected by western blotting in A549 cells transfected with mimic $\mathrm{NC}$ or various concentrations $(5,10$ and $20 \mathrm{nM})$ of miR-26a-5p. Data were presented as the mean $\pm \mathrm{SD}$. (B) ${ }^{* *} \mathrm{P}<0.01$ vs. mimic $\mathrm{NC}$ group. (C and $\left.\mathrm{D}\right){ }^{* *} \mathrm{P}<0.01$ vs. Control group; ${ }^{\#} \mathrm{P}<0.05,{ }^{\#} \mathrm{P}<0.01$ vs. LPS + mimic NC group. miR, microRNA; NC, negative control; LPS, lipopolysaccharide; CTGF, connective tissue growth factor; UTR, untranslated region; WT, wild-type; MT, mutant.

Recent studies have reported that miRNAs, as gene expression switches, have an important role in the progression of ALI $(18,19)$. A recent study has indicated that miR-802 was expressed at a low level in LPS-induced ALI and alleviated LPS-induced ALI by targeting Peli2 (20). Another recent study has revealed that miR-539-5p was underexpressed in sepsis-induced ALI and could protect mice from ALI (21). In the present study, the expression of miR-26a-5p was downregulated in LPS-induced ALI models in vivo and in vitro. It should be noted that miR-26a-5p has an important role in several injury models. For instance, Wei et al (22) have reported that miR-26a-5p overexpression could improve cerebral ischemia/reperfusion injury via attenuating cell apoptosis. Xing et al (23) have indicated that miR-26a-5p could protect against myocardial ischemia/reperfusion injury by modulating the PTEN/PI3K/AKT pathway. However, the function of miR-26a-5p in LPS-induced ALI is unclear. The present data revealed that the overexpression of miR-26a-5p markedly improved LPS-induced ALI by reducing the histopathological changes and W/D ratio in lung tissues, and thereby helped to improve the survival of ALI mice.

Previous studies have indicated that ALI is featured with the production of inflammatory factors, inflammatory cell infiltration and pulmonary epithelial cell apoptosis $(24,25)$. Evidence from several clinical studies has indicated that TNF- $\alpha$, IL- $1 \beta$ and IL- 6 are the main inflammatory cytokines actively secreted in response to the inflammatory cascade in ALI $(21,26)$. Previous studies have indicated that the excess inflammatory cytokines, such as TNF- $\alpha$, IL- 6 and IL-1 $\beta$, ultimately cause cell death via apoptosis and pyroptosis (27).
In addition, an increasing number of studies have demonstrated that miRNAs could exert a protective effect against LPS-induced ALI by inhibiting lung inflammation and pulmonary epithelial cell apoptosis. For example, miR-27a could alleviate lung inflammation and apoptosis in LPS-induced ALI mice by modulating the TLR4/MyD88/NF- $\mathrm{KB}$ pathway (28). Suo et al (29) have confirmed that miR-1246 could suppress ALI-induced inflammation and apoptosis by modulating NF- $\kappa B$ and Wnt/ $\beta$-catenin pathways. In addition, miR-26a-5p is considered to be associated with inflammation and apoptosis in numerous diseases. For example, the overexpression of miR-26a-5p could markedly suppress neuropathic pain and neuroinflammation in rats with chronic sciatic nerve injury (30). Wen et al (31) have suggested that miR-26a-5p significantly decreased myocardial cell apoptosis and expression of inflammatory factors in acute myocardial infarction by targeting ADAM17. The present study also demonstrated that the overexpression of miR-26a-5p significantly decreased LPS-induced apoptosis and inflammatory factor expression levels in both ALI mice and cell models, which suggests that miR-26a-5p could exert a protective effect against LPS-induced ALI by inhibiting apoptosis and inflammatory responses.

CTGF, also referred to as $\mathrm{CCN}$ family protein 2 (CCN2) and one of six members of cysteine-rich, secreted, heparin-binding proteins with a modular structure, has an important role in tissue remodeling and fibrosis (32). Increasingly, research has indicated that CTGF is a downstream mediator of TGF- $\beta 1$ that induces connective tissue cell proliferation and extracellular matrix deposition (8). The overexpression of CTGF has been 


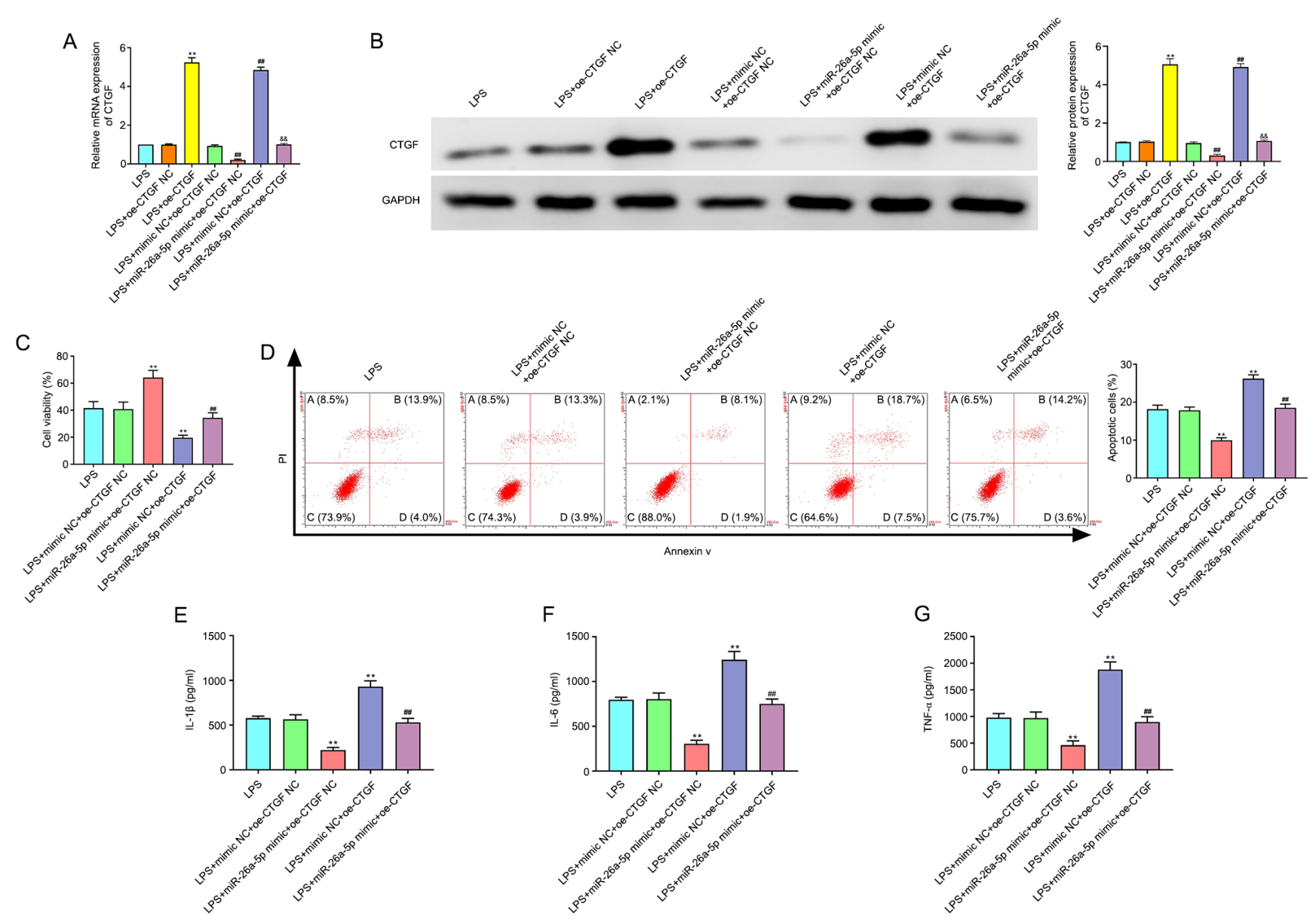

Figure 6. CTGF overexpression reverses the effect of miR-26a-5p on the apoptosis and inflammatory responses in LPS-induced A549 cells. A549 cells were co-transfected with miR-26a-5p mimic $(10 \mathrm{nM})$, oe-CTGF $(10 \mathrm{nM})$, mimic NC (10 nM) and oe-CTGF NC $(10 \mathrm{nM})$, and then treated with LPS for $24 \mathrm{~h}$, followed by the assessment of cell apoptosis and inflammatory response. (A) The mRNA expression of CTGF was detected by reverse transcription-quantitative PCR in transfected A549 cells. (B) The protein expression of CTGF was measured by western blotting in transfected A549 cells. (C) Cell viability was detected by MTT assay in transfected A549 cells. (D) The cell apoptosis was detected by flow cytometry in transfected A549 cells. The expression levels of (E) IL-1 $1 \beta$, (F) IL-6 and (G) TNF- $\alpha$ were detected by ELISA in transfected A549 cells. Data were presented as the mean \pm SD. (A and B) ${ }^{* *} \mathrm{P}<0.01$ vs. LPS + oe-CTGF NC group; ${ }^{\# \#} \mathrm{P}<0.01$ vs. LPS + mimic NC + oe-CTGF NC group; ${ }^{\& \&} \mathrm{P}<0.01$ vs. LPS + miR-26a-5p mimic + oe-CTGF NC or LPS + mimic NC + oe-CTGF group. (C-G) ${ }^{* *} \mathrm{P}<0.01$ vs. LPS + mimic NC + oe-CTGF NC group; ${ }^{\# \#} \mathrm{P}<0.01$ vs. LPS + miR-26a-5p mimic + oe-CTGF NC or LPS + mimic NC + oe-CTGF group. miR, microRNA; NC, negative control; LPS, lipopolysaccharide; CTGF, connective tissue growth factor; oe, overexpression plasmid.

observed in numerous fibrotic tissues, including kidney, lung, heart and liver, whereas in normal adult tissues or cells expression is at low or even undetectable levels (33). The present data also revealed that the expression of CTGF was significantly upregulated in LPS-induced A549 cells. Previous studies have indicated that inhibiting the upregulation of CTGF could attenuate bleomycin-induced ALI and pulmonary fibrosis (34). Furthermore, previous studies have reported that anti-CTGF therapy with neutralizing CTGF monoclonal antibodies could improve bleomycin-induced or radiation-induced lung fibrosis $(9,35)$. Evidence from several studies has suggested that miRNAs, such as miR-18a and miR-26a, could modulate lung injury and lung fibrosis via the regulation of CTGF $(12,36)$. Furthermore, a study by Li et al (37) has revealed that miR-26a-5p could alleviate pneumonia by targeting CTGF. The present data also confirmed that miR-26a-5p could negatively modulate the expression of CTGF. In addition, the present results also revealed that CTGF overexpression significantly reversed the effect of miR-26a-5p on cell apoptosis and inflammatory cytokines in LPS-induced A549 cells. Collectively, these results indicated that miR-26a-5p could inhibit apoptosis and inflammatory responses via targeting CTGF in LPS-induced ALI.

In summary, the present study confirmed that the expression of miR-26a-5p was downregulated in LPS-induced ALI mice and in A549 cells, while CTGF expression was upregulated. In addition, miR-26a-5p was demonstrated to attenuate lung inflammation and apoptosis in LPS-induced ALI by targeting CTGF. The findings of the present study provide new perspectives on miRNA-based diagnostic approaches against LPS-induced ALI. A key limitation of the present study was that only the effect of miR-26a-5p on CTGF expression was assessed; therefore, further investigation is required to verify the protective effect of miR-26a-5p against LPS-induced ALI.

\section{Acknowledgements}

Not applicable.

\section{Funding}

No funding was received. 


\section{Availability of data and materials}

The datasets used and analyzed during the current study are available from the corresponding author on reasonable request.

\section{Authors' contributions}

ZF designed and conceived the study. HL and TY performed the research, analyzed data and wrote the manuscript. All authors have read and approved the final version of the manuscript.

\section{Ethics approval and consent to participate}

The protocol of this research has been approved by the Ethics Committee of Zibo Women \& Children Hospital. The experimental procedures were performed in accordance with the Guide for the Care and Use of Laboratory Animals and approved by the Ethics Committee of Zibo Women \& Children Hospital.

\section{Patient consent for publication}

Not applicable.

\section{Competing interests}

The authors declare that they have no competing interests.

\section{References}

1. Needham DM, Wozniak AW, Hough CL, Morris PE, Dinglas VD, Jackson JC, Mendez-Tellez PA, Shanholtz C, Ely EW, Colantuoni E, et al: Risk factors for physical impairment after acute lung injury in a national, multicenter study. Am J Respir Crit Care Med 189: 1214-1224, 2014.

2. Pan C, Liu L, Xie JF and Qiu HB: Acute respiratory distress syndrome: Challenge for diagnosis and therapy. Chin Med J (Engl) 131: 1220-1224, 2018.

3. Bartel DP: MicroRNAs: Target recognition and regulatory functions. Cell 136: 215-233, 2009.

4. Pattarayan D, Thimmulappa RK, Ravikumar V and Rajasekaran S: Diagnostic Potential of extracellular microRNA in respiratory diseases. Clin Rev Allergy Immunol 54: 480-492, 2018.

5. Yang Y, Liu D, Xi Y, Li J and Liu B: Upregulation of miRNA-140-5p inhibits inflammatory cytokines in acute lung injury through the MyD88/NF- $\kappa \mathrm{B}$ signaling pathway by targeting TLR4. Exp Ther Med 16: 3913-3920, 2018.

6. Xie W, Lu Q, Wang K, Lu J, Gu X, Zhu D, Liu F and Guo Z: miR-34b-5p inhibition attenuates lung inflammation and apoptosis in an LPS-induced acute lung injury mouse model by targeting progranulin. J Cell Physiol 233: 6615-6631, 2018.

7. Bradham DM, Igarashi A, Potter RL and Grotendorst GR: Connective tissue growth factor: A cysteine-rich mitogen secreted by human vascular endothelial cells is related to the SRC-induced immediate early gene product CEF-10. J Cell Biol 114: 1285-1294, 1991.

8. Blom IE, Goldschmeding R and Leask A: Gene regulation of connective tissue growth factor: New targets for antifibrotic therapy? Matrix Biol 21: 473-482, 2002.

9. Alapati D, Rong M, Chen S, Hehre D, Rodriguez MM, Lipson KE and $\mathrm{Wu} \mathrm{S}$ : Connective tissue growth factor antibody therapy attenuates hyperoxia-induced lung injury in neonatal rats. Am J Respir Cell Mol Biol 45: 1169-1177, 2011.

10. Guo H, Ji F, Liu B, Chen X, He J and Gong J: Peiminine ameliorates bleomycin-induced acute lung injury in rats. Mol Med Rep 7: 1103-1110, 2013.

11. Zhou T, Yu Q, Lin H, Wang Z, Fu G, Lei L, Shi Y, Zhang L, Qin L and Liu Y: The Role of CTGF in inflammatory responses induced by silica particles in human bronchial epithelial cells. Lung 197: 783-791, 2019.
12. Yang H, Li W, Zhang Y, Li M, Gao Y, Lao C and Shi B: Regulatory role of miR-18a to CCN2 by TGF- $\beta 1$ signaling pathway in pulmonary injury induced by nano- $\mathrm{SiO}_{2}$. Environ Sci Pollut Res Int 25: 867-876, 2018.

13. Qi D, He J, Wang D, Deng W, Zhao Y, Ye Y and Feng L: $17 \beta$-estradiol suppresses lipopolysaccharide-induced acute lung injury through PI3K/Akt/SGK1 mediated up-regulation of epithelial sodium channel $(\mathrm{ENaC})$ in vivo and in vitro. Respir Res 15: 159, 2014.

14. Agarwal V, Bell GW, Nam JW and Bartel DP: Predicting effective microRNA target sites in mammalian mRNAs. Elife 4: e05005, 2015.

15. Livak KJ and Schmittgen TD: Analysis of relative gene expression data using real-time quantitative PCR and the 2(-Delta Delta C(T)) method. Methods 25: 402-408, 2001.

16. Leung WS, Yang ML, Lee SS, Kuo CW, Ho YC, Huang-Liu R, Lin HW and Kuan YH: Protective effect of zerumbone reduces lipopolysaccharide-induced acute lung injury via antioxidative enzymes and Nrf2/HO-1 pathway. Int Immunopharmacol 46: 194-200, 2017.

17. Wang $\mathrm{Q}$ and Xiao L: Isochlorogenic acid $\mathrm{A}$ attenuates acute lung injury induced by LPS via Nf- $\kappa$ B/NLRP3 signaling pathway. Am J Transl Res 11: 7018-7026, 2019.

18. Guo H, Ingolia NT, Weissman JS and Bartel DP: Mammalian microRNAs predominantly act to decrease target mRNA levels. Nature 466: 835-840, 2010.

19. Li W, Qiu X, Jiang H, Han Y, Wei D and Liu J: Downregulation of miR-181a protects mice from LPS-induced acute lung injury by targeting Bcl-2. Biomed Pharmacother 84: 1375-1382, 2016.

20. You Q, Wang J, Jia D, Jiang L, Chang Y and Li W: MiR-802 alleviates lipopolysaccharide-induced acute lung injury by targeting Peli2. Inflamm Res 69: 75-85, 2020.

21. Meng L, Cao H, Wan C and Jiang L: MiR-539-5p alleviates sepsis-induced acute lung injury by targeting ROCK1. Folia Histochem Cytobiol 57: 168-178, 2019.

22. Wei R, Zhang L, Hu W, Wu J and Zhang W: Long non-coding RNA AK038897 aggravates cerebral ischemia/reperfusion injury via acting as a ceRNA for miR-26a-5p to target DAPK1. Exp Neurol 314: 100-110, 2019.

23. Xing X, Guo S, Zhang G, Liu Y, Bi S, Wang X and Lu Q: miR-26a-5p protects against myocardial ischemia/reperfusion injury by regulating the PTEN/PI3K/AKT signaling pathway. Braz J Med Biol Res 53: e9106, 2020.

24. Cox R Jr, Phillips O, Fukumoto J, Fukumoto I, Parthasarathy PT, Arias S, Cho Y, Lockey RF and Kolliputi N: Enhanced resolution of hyperoxic acute lung injury as a result of aspirin triggered resolvin D1 treatment. Am J Respir Cell Mol Biol 53: 422-435, 2015.

25. Liu F, Zhang W, Yang F, Feng T, Zhou M, Yu Y, Yu X, Zhao W, Yi F, Tang $\mathrm{W}$ and Lu Y: Interleukin-6-stimulated progranulin expression contributes to the malignancy of hepatocellular carcinoma cells by activating mTOR signaling. Sci Rep 6: 21260, 2016.

26. Ganter MT, Roux J, Miyazawa B, Howard M, Frank JA, Su G, Sheppard D, Violette SM, Weinreb PH, Horan GS, et al: Interleukin-1beta causes acute lung injury via alphavbeta5 and alphavbeta6 integrin-dependent mechanisms. Circ Res 102: 804-812, 2008.

27. Lv H, Liu Q, Wen Z, Feng H, Deng X and Ci X: Xanthohumol ameliorates lipopolysaccharide (LPS)-induced acute lung injury via induction of AMPK/GSK3 $\beta$-Nrf2 signal axis. Redox Biol 12: 311-324, 2017.

28. Ju M, Liu B, He H, Gu Z, Liu Y, Su Y, Zhu D, Cang J and Luo Z: MicroRNA-27a alleviates LPS-induced acute lung injury in mice via inhibiting in flammation and apoptosis through modulating TLR4/MyD88/NF-кB pathway. Cell Cycle 17: 2001-2018, 2018.

29. Suo T, Chen GZ, Huang Y, Zhao KC, Wang T and Hu K: miRNA-1246 suppresses acute lung injury-induced inflammation and apoptosis via the NF- $\kappa \mathrm{B}$ and $\mathrm{Wnt} / \beta$-catenin signal pathways. Biomed Pharmacother 108: 783-791, 2018.

30. Zhang Y, Su Z, Liu HL, Li L, Wei M, Ge DJ and Zhang ZJ: Effects of miR-26a-5p on neuropathic pain development by targeting MAPK6 in in CCI rat models. Biomed Pharmacother 107: 644-649, 2018

31. Wen X, Yin Y, Li X, He T, Wang P, Song M and Gao J: Effect of miR-26a-5p targeting ADAM17 gene on apoptosis, inflammatory factors and oxidative stress response of myocardial cells in hypoxic model. J Bioenerg Biomembr 52: 83-92, 2020.

32. Cicha I and Goppelt-Struebe M: Connective tissue growth factor: Context-dependent functions and mechanisms of regulation. Biofactors 35: 200-208, 2009. 
33. Gressner OA and Gressner AM: Connective tissue growth factor: A fibrogenic master switch in fibrotic liver diseases. Liver Int 28: 1065-1079, 2008.

34. Kim JW, Rhee CK, Kim TJ, Kim YH, Lee SH, Yoon HK, Kim SC, Lee SY, Kwon SS, Kim KH and Kim YK: Effect of pravastatin on bleomycin-induced acute lung injury and pulmonary fibrosis. Clin Exp Pharmacol Physiol 37: 1055-1063, 2010.

35. Ponticos M, Holmes AM, Shi-wen X, Leoni P, Khan K, Rajkumar VS, Hoyles RK, Bou-Gharios G, Black CM, Denton CP, et al: Pivotal role of connective tissue growth factor in lung fibrosis: MAPK-dependent transcriptional activation of type I collagen. Arthritis Rheum 60: 2142-2155, 2009.
36. Li X, Liu L, Shen Y, Wang T, Chen L, Xu D and Wen F: MicroRNA-26a modulates transforming growth factor beta-1-induced proliferation in human fetal lung fibroblasts. Biochem Biophys Res Commun 454: 512-517, 2014.

37. Li C, Han T, Li R, Fu L and Yue L: miR-26a-5p mediates TLR signaling pathway by targeting CTGF in LPS-induced alveolar macrophage. Biosci Rep 40: BSR20192598, 2020.

(c) (i) This work is licensed under a Creative Commons Attribution 4.0 International (CC BY 4.0) License. 